This is an electronic reprint of the original article. This reprint may differ from the original in pagination and typographic detail.

Author(s): Chen, Chengcong; Alén, Raimo; Lehto, Joni; Pakkanen, Hannu

Title: $\quad$ Combustion behavior of kraft black liquor droplets from hot water pretreated hardwood and softwood chips

Year: $\quad 2016$

Version:

Please cite the original version:

Chen, C., Alén, R., Lehto, J., \& Pakkanen, H. (2016). Combustion behavior of kraft black liquor droplets from hot water pretreated hardwood and softwood chips. Tappi Journal, 15(11), 685-691. https://doi.org/10.32964/TJ15.11.685

All material supplied via JYX is protected by copyright and other intellectual property rights, and duplication or sale of all or part of any of the repository collections is not permitted, except that material may be duplicated by you for your research use or educational purposes in electronic or print form. You must obtain permission for any other use. Electronic or print copies may not be offered, whether for sale or otherwise to anyone who is not an authorised user. 


\title{
Combustion behavior of kraft black liquor droplets from hot-water pretreated hardwood and softwood chips
}

\author{
CHENGCONG CHEN, RAIMO ALÉN, JONI LEHTO, AND HANNU PAKKANEN \\ Laboratory of Applied Chemistry, University of Jyväskylä, FI-40014, Finland
}

\begin{abstract}
This paper describes the combustion properties of birch and spruce kraft black liquors obtained from an integrated forest biorefinery concept in which a hot-water extraction of chips was performed prior to pulping. This pretreatment, aiming mainly at the recovery of various hemicelluloses-derived materials, increased the concentrations of lignin and hydroxy acids in black liquors, compared to those in the reference black liquors without any process modification. On the other hand, the pretreatment decreased the concentrations of volatile acids and other organics (extractives and hemicellulose residues). Due to these characteristic changes, the total burning times (pyrolysis time plus char burning time) of the reference black liquors were somewhat longer than those of black liquors from the modified cooking process. It was also shown that the novel biorefinery-based black liquors swell more than the conventional ones. This phenomenon was concluded to be primarily associated with the combined effect of high-molarmass lignin fragments and hydroxy acids. All of the detected changes in combustion behavior were more intense for birch black liquors than for spruce black liquors.
\end{abstract}

Application: This study clarifies various effects caused by the typical hot-water pretreatment of hardwood and softwood chips prior to kraft pulping on the combustion properties of black liquor.

KEYWORDS: Black liquor, Hot-water pretreatment, Lignin, Aliphatic carboxylic acids, Combustion properties.

\section{INTRODUCTION}

Kraft pulping is the dominant delignification process in the production of fiber for papermaking $[1,2]$. In this process, an aqueous hot-alkali solution reacts with the feedstock, resulting in a 
cooking yield of about $50 \%$ of the initial dry solids, where the spent cooking liquor or black liquor (BL) with a dry solids content of 10-15\% after delignification is the most important byproduct. BL contains, in addition to water and residual cooking chemicals, significant amounts of lignin-derived fragments and carbohydrates-derived aliphatic carboxylic acids together with some hemicellulose residues and extractives [3,4]. In practice, for environmental and economic reasons, after evaporation (dry solids content is increased to $65-85 \%$ ) BL is burned in a Tomlinson-type recovery furnace as sprayed droplets to recover cooking chemicals and to generate energy [5]. Laboratory studies under controlled conditions on the combustion properties of BL have traditionally divided the burning process of a single droplet into sequential stages [6,7]: drying, pyrolysis (i.e., devolatilization including specific swelling), char burning, and inorganic coalescence. All of these stages are important factors in the design and operation of a recovery boiler, and the results obtained from laboratory-scale tests have also explained much about the combustion behavior of different BLs.

It has been shown that the combustion properties of BL are greatly affected by operating conditions in the recovery furnace as well as the liquor composition [8-18], for example, by wood species, pulping method, and possible heating treatment of BL. In fact, due to the influence of these variables on the chemical composition of BL dry solids [4,19], they also play an important role in the combustion properties of BL. According to the integrated forest biorefinery concept $[4,20]$, the existing pulp mill has been considered to be capable of producing novel value-added by-products. Recently, the most common alternatives studied have been to introduce either an acidic or alkaline pretreatment stage prior to alkaline pulping, mainly for recovering various carbohydrate-derived materials from the chips [4,21-31]. These types of pretreatment processes have an influence on the main delignification process and thereby the chemical composition of the final BL. For this reason, it can be concluded that pretreatments also cause some variations in the combustion properties of BL. However, there are only limited fundamental data available on these changes.

The aim of this investigation was to study the combustion properties of kraft BLs prepared from hot-water pretreated birch and spruce chips. Combustion experiments were carried out with single BL droplets in stagnant air at $800^{\circ} \mathrm{C}$ in a laboratory furnace. 


\section{EXPERIMENTAL}

\section{Pretreatment and pulping}

Laboratory-scale hot-water pretreatments (HWPs) of screened silver birch (Betula pendula) and Norway spruce (Picea abies) chips were conducted in 1.25-L rotating stainless steel autoclaves heated in an oil bath (CRS Autoclave System 420) [31]. Chips were treated at $150^{\circ} \mathrm{C}$ for 60 minutes, and the liquor-to-wood ratio was $4.5 \mathrm{~L} / \mathrm{kg}$. The HWP yields for birch and spruce chips were $83.0 \%$ and $90.7 \%$, respectively.

Kraft BLs were prepared by cooking both untreated and pretreated birch and spruce wood chips in the same laboratory-scale digester as above (Table I). At the end of each cook, the autoclave was removed from the oil bath and cooled rapidly in cold tap water. The BL was then separated from the pulp by pressing, and the pulp was thoroughly washed with tap water. Pulp yield was calculated on the basis of oven-dry (o.d.) feedstock and pulp and kappa number of pulps was determined according to standard test method SCAN-C 1:00. The BLs were stored in a freezer prior to analyses and combustion tests.

\section{Black liquor analyses}

Analyses of lignin and aliphatic carboxylic acids ("volatile" acetic and formic acids and "nonvolatile" hydroxy acids) in the black liquors were conducted as follows.

After dilution with $0.1 \mathrm{M}$ aqueous $\mathrm{NaOH}$, the lignin content was estimated by $\mathrm{UV} / \mathrm{V}$ is spectrometry at $280 \mathrm{~nm}$ using an absorptivity value of $22.8 \mathrm{~L} /(\mathrm{g} \cdot \mathrm{cm})$ and $24.3 \mathrm{~L} /(\mathrm{g} \cdot \mathrm{cm})$ for birch

and spruce liquors, respectively [32]. A gel permeation chromatographic (GPC) system (a Waters HPLC equipped with a Superdex 75 gel column using $0.1 \mathrm{M}$ aqueous $\mathrm{NaOH}$ as the eluent) was applied to determine the molar masses (MMs) [33].

Volatile and hydroxy acids were determined by gas chromatography (GC/FID and GC/MSD) as their benzyl esters [34] and per(trimethylsilyl)ated derivatives [35], respectively.

The overall content of extractives and other organics (e.g., hemicellulose residues) was evaluated by subtracting the amounts of lignin and aliphatic carboxylic acids from the total dissolved organic material.

The residual alkali was determined according to KCL procedure (number 67a:87) by titrating the diluted and carbonate-buffered black liquor sample to $\mathrm{pH} 11.5$ with $1 \mathrm{M}$ hydrochloric acid. 


\section{Droplet combustion tests}

BL samples were evaporated under reduced pressure at $40^{\circ} \mathrm{C}$ to a dry solids content of 55-75\%. Fifteen to twenty individual droplets around $9 \mathrm{mg}$ in mass were burnt in a laboratory furnace at $800^{\circ} \mathrm{C}$ in the stagnant air [17]. The process of droplet combustion was recorded by a high definition video camera. Pyrolysis and char burning times $(\mathrm{s} / \mathrm{mg}$ ) were obtained from the video recording with the assistance of the VirtualDub software. The maximum swelling of each droplet $\left(S_{\max }\right.$ as $\mathrm{cm}^{3} / \mathrm{g}$ ) was calculated based on an approximation of the swollen particle as an ideal sphere:

$$
S_{\max }=\frac{4}{3} A \sqrt{\frac{A}{\pi}} / g,
$$

where $\mathrm{A}$ is the sectional area of the swollen particle measured from a selected frame of the video recording (at the point of maximum swelling) by the ImageJ software and $g$ is the dry mass of droplet.

\section{RESULTS AND DISCUSSION}

\section{Chemical composition of black liquors}

Table II presents the organic composition of all studied BLs. It is known that during alkaline pulping, in addition to a significant degradation and dissolution of lignin, a substantial amount of polysaccharides (mainly hemicelluloses) is converted to soluble aliphatic carboxylic acids by various alkali-catalyzed degradation reactions $[3,36]$. The results clearly indicated the effect of wood species on the acid formation (B52 and B65 vs. S65 and S85), since 2-hydroxybutanoic and xyloisosaccharinic acids mainly originated from xylan-rich birch while glucoisosaccharinic acid mainly originated from glucomannan-rich spruce. Acetic acid was mostly formed by deacetylation of the acetyl groups of hemicelluloses and its higher amount in birch BL, compared to that in spruce BL, was due to the higher content of acetyl groups in birch xylan than in spruce glucomannan. Of the main other acids, formic, glycolic, and lactic acids were unspecifically formed from all the polysaccharide constituents present in feedstocks. Also, it was noted that the cooking time did not affect much the liquor compositions (B52 vs. B65 and S65 vs. S85) and only a slight increase in the concentration of lignin as well as acids was detected in the course of prolonged delignification. In addition, the decrease in residual alkali (Table I) 
distinctly suggested the enhanced formation of hydroxy acids in the kraft pulping of the pretreated birch chips, while this phenomenon was not seen for spruce.

Figure 1 compares the variations in BL compositions including lignin, hydroxy acids, volatile acids, and other organics. The HWP of chips typically increased the content of lignin and hydroxy acids in all BLs. An increase (an absolute increase of 30-40\% for birch and about $15 \%$ for spruce) in hydroxy acids (B52 vs. HW + B52, B65 vs. HW + B65, S65 vs. HW + S65, and S85 vs. HW + S85) could be primarily explained by the partial removal of acetyl groups from hemicelluloses already during the HWP stage [29]. For this reason, less alkali, compared to traditional cooking without the HWP stage, was needed for the hydrolysis of acetyl groups (i.e., neutralization of acetic acid) in the cooking stage, thus offering more alkali (i.e., higher alkalinity) for other degradation reactions of polysaccharide chains.

The HWP stage also caused morphological changes to the chip matrix, making it more accessible to various alkali-catalyzed reactions during pulping [31,37]. As a result of this increase in accessibility, higher amounts of dissolved lignin in BLs from the pretreated chips (about $30 \%$ for birch and 15\% for spruce), compared to their untreated counterparts, were obtained (Fig. 1). In addition, after the HWP, the increment of lignin (4-9\%) based on the total dissolved organics (Table II) was higher than that of hydroxy acids (1-5\%), suggesting a more pronounced increase in the mass portion of lignin in BLs. Unlike lignin and hydroxy acids, the contents of volatile acids and other organics showed a declining trend, although, despite deacetylation in the HWP stage, the concentration of acetic acid especially in birch BLs was still rather high.

Molar mass distributions (MMDs) of lignin characteristically indicated the influence of cooking time as observed earlier by Pakkanen and Alén [33] (Table III and Fig. 2). It was also noticed that during the HWP, lower-MM lignin fragments were primarily removed, and the removal of high-MM lignin fragments took place more readily during the subsequent cooking phase. Therefore, a slightly more significant proportion of higher-MM lignin fragments was typically found in BLs from pretreated chips than in those from untreated chips.

\section{Combustion properties of black liquor droplets}

Figure 3 summarizes the combustion properties of all the BLs studied, indicating their pyrolysis, char burning, and total burning (i.e., pyrolysis time plus char burning time) times together with 
specific maximum swelling. It was noted that in particular for birch, the BLs from the pretreated chips had a higher swelling capacity than those from untreated chips. This phenomenon was considered to be mainly associated, on the one hand, with higher lignin contents (Table II) and, on the other hand, higher contents of high-MM lignin fragments $(>10,000 \mathrm{~g} / \mathrm{mol})$ were also important for the formation of char [4,38]. In addition, the BLs from pretreated chips contained higher amounts of hydroxy acids (Table II), which degrade faster than lignin when heated, thus readily releasing rapidly volatile degradation products [39]. It has been shown earlier [12] that hardwood kraft lignin swells considerably more than softwood kraft lignin when mixed with hydroxy acids. One further aspect is also that hardwood black liquors typically contain more xylan residues, which have an increasing effect on swelling [4].

Figure 3 also illustrates the "swelling profile" of the liquor droplets B65 and HW + B65, clearly indicating that in the case of $\mathrm{HW}+\mathrm{B} 65$, a shorter pyrolysis time was needed to reach maximum swelling. The mechanism behind this higher swelling rate for $\mathrm{HW}+\mathrm{B} 65$ was probably due to the combined effect of high-MM lignin fragments and hydroxy acids [4].

Shorter char burning times together with enhanced swelling (Fig. 3) were observed for BLs $(\mathrm{HW}+\mathrm{B} 52$ and $\mathrm{HW}+\mathrm{B} 65)$ from pretreated chips than those (B52 and B65) from untreated chips. This could be explained by the hypothesis that a larger surface is more favorable for the faster char burning [16]. It should be also pointed out that lignin is the main component of BL organics with the highest tendency to form char $[39,40]$, thus explaining the longer duration of char burning than that of pyrolysis. A char burning rate is significant for phenomena occurring in the char bed, where gasification of carbon and reduction of sodium sulfate are of importance [5]. In contrast, the HWP of spruce chips seemed not to greatly affect the pyrolysis or char burning times of the corresponding BLs (S65 vs. HW + S65 and S85 vs. HW + S85). In general, it was concluded that the conventional BLs have the longest total burning times and that birch BLs burned faster than spruce BLs.

\section{CONCLUSIONS}

This study shows new data on the combustion properties of birch and spruce kraft BLs obtained from an integrated forest biorefinery concept applying hot-water extraction to chips prior to kraft pulping. Compared to the conventional BLs from untreated chips, the chemical composition of BLs from pretreated chips varied characteristically; in the latter case, higher concentrations of 
lignin and hydroxy acids were detected, whereas the concentrations of volatile acids and other organics (extractives and polysaccharides) were lower. In particular, the total burning times (pyrolysis time plus char burning time) of the conventional BLs obtained without any process modification were somewhat longer than those of BLs from the integrated biorefinery concept. It was also shown that the modified BLs swelled more than the conventional ones, which was probably due to the combined effect of high-MM lignin fragments and hydroxy acids. However, the effect of the MMD of lignin on the combustion properties of BL will be studied in forthcoming studies. All of the changes in combustion behavior were more intense for birch BLs than for spruce BLs, thus having a minor influence on the operation of the recovery furnace in the latter case.

\section{ACKNOWLEDGEMENTS}

Financial support from the Academy of Finland, within the framework of the International Doctoral Programme in Bioproducts Technology (PaPSaT) is gratefully acknowledged. Special thanks are due to Mrs. Marja Salo for her assistance with the analyses of aliphatic carboxylic acids.

\section{LITERATURE CITED}

1. Rydholm, S.A., Pulping Processes, Interscience Publishers, New York, NY, USA, 1965.

2. Grace, T.M., Malcom, E.W., and Kocurek, M.J., Eds., Pulp and Paper Manufacture, Volume 5, Alkaline Pulping, $3^{\text {rd }}$ edition, Joint Textbook Committee of the Paper Industry, TAPPI and CPPA, USA and Canada, 1989.

3. Sjöström, E., Wood Chemistry - Fundamentals and Applications, Academic Press, $2^{\text {nd }}$ edition, San Diego, CA, USA, 1993.

4. Alén, R., in Biorefining of Forest Resources (R. Alén, Ed.), Paper Engineers' Association, Helsinki, Finland, 2011, pp. 55-114.

5. Adams, T.N., Ed., Kraft Recovery Boilers, TAPPI PRESS, Atlanta, GA, USA, 1997.

6. Hupa, M., Solin, P., and Hyöty, P., J. Pulp Paper Sci. 13(2): 67(1987).

7. Frederick, W., Noopila, T., and Hupa, M., J. Pulp Paper Sci. 17(5): J164(1991).

8. Whitty, K., Backman, R., and Hupa, M., Biores. Technol. 99(3): 663(2008).

9. Miller, P., Clay, D., and Lonsky, W., Chem. Eng. Commun. 75(1): 101(1989). 
10. Vakkilainen, E., Backman, R., Forssén, M., and Hupa, M., Pulp Paper Can. 100(8): 24(1990).

11. Noopila, T., Alén, R., and Hupa, M., J. Pulp Paper Sci. 17(4): J105(1991).

12. Alén, R., Hupa, M., and Noopila, T., Holzforschung 46(4): 337(1992).

13. Frederick, W.J. and Hupa, M., J. Pulp Paper Sci. 20(10): 274(1994).

14. Alén, R., Biores. Technol. 49(2): 99(1994).

15. Alén, R., J. Pulp Paper Sci. 23(2): J62(1997).

16. Whitty, K., Backman, R., Forssén, M., Hupa, M., Rainio, J., and Sorvari, V., J. Pulp Paper Sci. 23(3): J119(1997).

17. Louhelainen, J., "Changes in the Chemical Composition and Physical Properties of Wood and Nonwood Black Liquors during Heating", Ph.D. Thesis, University of Jyväskylä, Laboratory of Applied Chemistry, Jyväskylä, Finland, 2003.

18. Vähä-Savo, N., Demartini, N., Ziesig, R., Tomani, P., Theliander, H., Välimäki, E., and Hupa, M., TAPPI J. 13(8): 81(2014).

19. Sjöström, E. and Alén, R., Eds., Analytical Methods in Wood Chemistry, Pulping and Papermaking, Springer, Heidelberg, Germany, 1999.

20. van Heiningen, A., Pulp Paper Can. 107(6): 38(2006).

21. Wayman, M. and Chua, M.G.S., Can. J. Chem. 57(19): 2612(1979).

22. Mosier, N., Wyman, C., Dale, B., Elander, R., Lee, Y.Y., Holtzapple, M., and Ladisch, M., Biores. Technol. 96(6): 673(2005).

23. Kamm, B., Kamm, M., Gruber, P.R., and Kromus, S., in Biorefineries - Industrial Processes and Products, Status Quo and Future Directions, Vol. 1 (B. Kamm, P.R. Gruber, and M. Kamm, Eds.), Wiley-VCH, Weinheim, Germany, 2006, pp. 3-40.

24. Carvalheiro, F., Duarte, L.C., and Círio, F.M., J. Sci. Ind. Res. 67(11): 849(2008).

25. Yoon, S.-H., Macewan, K., and van Heiningen, A., TAPPI J. 7(6): 27(2008).

26. Walton, S.L., Hutto, D., Genco, J.M., van Walsum, G.P., and van Heiningen, A.R., Ind. Eng. Chem. Res. 49(24): 12638(2010).

27. Park, Y.C. and Kim, J.S., Energy 47(1): 31(2012).

28. Lehto, J. and Alén, R., J. Wood Chem. Technol. 33(2): 77(2013).

29. Lehto, J., Alén, R., and Malkavaara, P., BioResources 9(1): 93(2014).

30. Lehto, J., Alén, R., and Malkavaara, P., BioResources, 9(3): 4958(2014). 
31. Lehto, J., "Advanced Biorefinery Concepts Integrated to Chemical Pulping", Ph.D. Thesis, University of Jyväskylä, Laboratory of Applied Chemistry, Jyväskylä, Finland, 2015.

32. Alén, R. and Hartus, T., Cellul. Chem. Technol. 22(6): 613(1988).

33. Pakkanen, H. and Alén, R., J. Wood Chem. Technol. 32(4): 279(2013).

34. Alén, R., Jännäri, P., and Sjöström, E., Finn. Chem. Lett. 12(5): 190(1985).

35. Alén, R., Niemelä, K., and Sjöström, E., J. Chromatogr. A. 301(1): 273(1984).

36. Alén, R., in Forest Products Chemistry (P. Stenius, Ed.), Fapet Oy, Helsinki, Finland, 2000, pp. 58-104.

37. Hendriks, A.T.W.M. and Zeeman, G., Biores. Technol. 100(1): 10(2009).

38. Cagnon, B., Py, X., Guillot, A., Stoeckli, F., and Chambat, G., Biores. Technol. 100(1): 292(2009).

39. Alén, R., Rytkönen, S., and McKeough, P., J. Anal. Appl. Pyrolysis 31: 1(1995).

40. Yang, H., Yan, R., Chen, H., Lee, D.H., and Zheng, C., Fuel 86(12-13): 1781(2007). 
I. Kraft pulping of the untreated and hot-water pretreated $(\mathrm{HW})$ birch (B) and spruce (S) chips.

\begin{tabular}{|l|c|c|c|c|c|c|c|c|}
\hline Parameter & B52 & B65 & HW+B52 & HW+B65 & S65 & S85 & HW+S65 & HW+S85 \\
\hline $\begin{array}{l}\text { Effective alkali as NaOH, } \\
\text { \% on o.d. wood }\end{array}$ & \multicolumn{7}{|c|}{35} \\
\hline Sulfidity, \% & \multicolumn{7}{|c|}{49} \\
\hline Liquor-to-wood ratio, L/kg & \multicolumn{7}{|c|}{4.5} \\
\hline Max. cooking temperature, ${ }^{\circ} \mathrm{C}$ & \multicolumn{7}{|c|}{18} & \multicolumn{5}{|c|}{170} \\
\hline Cooking time, min & 52 & 65 & 52 & 65 & 65 & 85 & 65 & 85 \\
\hline H factor & 500 & 600 & 500 & 600 & 1,200 & 1,500 & 1,200 & 1,500 \\
\hline Pulping yield, \% & 55.8 & 55.6 & 51.3 & 49.8 & 52.8 & 51.2 & 49.2 & 48.0 \\
\hline Residual alkali, g/L & 6.8 & 6.0 & 4.7 & 3.9 & 9.3 & 9.3 & 9.5 & 9.5 \\
\hline Kappa number & 31.7 & 25.9 & 16.6 & 16.3 & 42.7 & 38.3 & 36.1 & 32.9 \\
\hline
\end{tabular}

II. Chemical composition of organic dry solids in birch and spruce kraft BLs (g/L). For abbreviations, see Table I.

\begin{tabular}{|l|cccc|cccc|}
\hline Component & B52 & B65 & HW + B52 & HW + B65 & S65 & S85 & HW + S65 & HW + S85 \\
\hline Volatile acids & 19.8 & 20.0 & 16.9 & 16.8 & 10.5 & 10.9 & 9.4 & 9.7 \\
Formic & 4.4 & 4.5 & 6.5 & 6.4 & 5.2 & 5.5 & 5.8 & 5.9 \\
Acetic & 15.4 & 15.5 & 10.4 & 10.4 & 5.3 & 5.4 & 3.6 & 3.8 \\
\hline Hydroxy acids & 15.2 & 16.3 & 21.5 & 22.2 & 20.9 & 21.5 & 23.8 & 24.8 \\
Glycolic & 0.8 & 0.8 & 1.2 & 1.3 & 1.4 & 1.4 & 1.4 & 1.5 \\
Lactic & 1.7 & 1.8 & 2.2 & 2.4 & 3.3 & 3.5 & 3.4 & 3.5 \\
2-Hydroxybutanoic & 4.1 & 4.2 & 4.9 & 5.2 & 0.9 & 1.0 & 1.5 & 1.7 \\
Xyloisosaccharinic & 2.5 & 2.6 & 4.8 & 4.9 & 0.5 & 0.5 & 1.5 & 1.6 \\
Glucoisosaccharinic & 2.1 & 2.2 & 2.6 & 2.8 & 8.1 & 8.0 & 8.8 & 9.1 \\
Others* & 4.0 & 4.7 & 5.8 & 5.6 & 6.7 & 7.1 & 7.2 & 7.4 \\
\hline Lignin & 45.3 & 48.0 & 59.8 & 61.2 & 61.0 & 62.6 & 69.8 & 72.0 \\
\hline Other organics & 18.1 & 14.4 & 10.1 & 11.4 & 12.6 & 13.5 & 10.0 & 9.0 \\
\hline Volatile acids-to-total organics & 0.20 & 0.20 & 0.16 & 0.15 & 0.10 & 0.10 & 0.08 & 0.08 \\
\hline Hydroxy acids-to-total organics & 0.15 & 0.17 & 0.20 & 0.20 & 0.20 & 0.20 & 0.21 & 0.21 \\
\hline Lignin-to-total organics & 0.46 & 0.49 & 0.55 & 0.55 & 0.58 & 0.58 & 0.62 & 0.62 \\
\hline
\end{tabular}

*Mainly 3,4-dideoxy- and 3-deoxy-pentonic acids.

III. Molar mass distribution of dissolved kraft lignins (\% of total lignin). For abbreviations, see Table I.

\begin{tabular}{|c|cccc|cccc|}
\hline Molar mass, g/mol & B52 & B65 & HW + B52 & HW + B65 & S65 & S85 & HW + S65 & HW + S85 \\
\hline$>10,000$ & 38.8 & 60.2 & 53.0 & 63.6 & 40.3 & 57.0 & 50.8 & 59.2 \\
\hline $5,000-10,000$ & 20.8 & 17.3 & 19.1 & 17.0 & 17.5 & 19.1 & 21.2 & 18.7 \\
\hline $3,500-5,000$ & 11.0 & 6.6 & 8.2 & 6.2 & 9.9 & 7.3 & 8.9 & 6.9 \\
\hline$<3,500$ & 29.4 & 15.9 & 19.7 & 13.2 & 32.3 & 16.6 & 19.1 & 15.2 \\
\hline
\end{tabular}




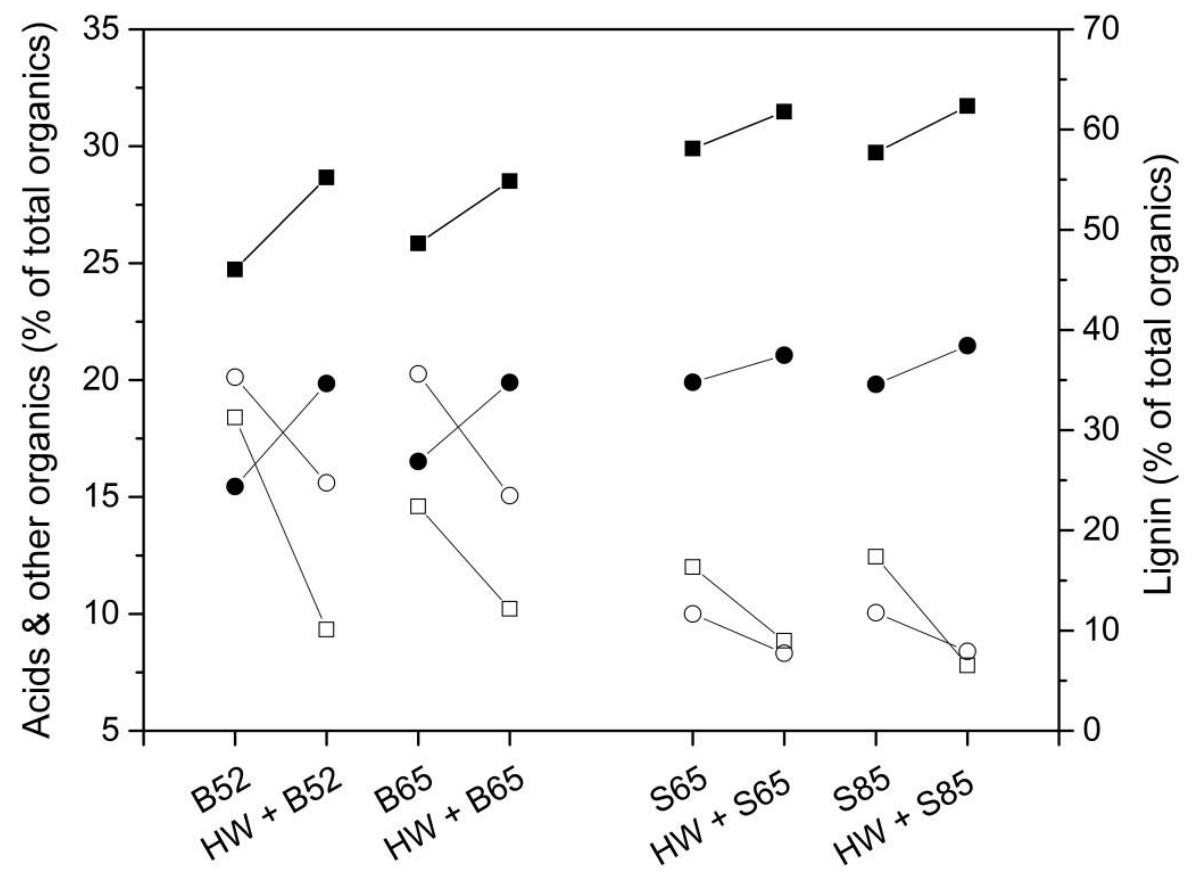

Note: $\mathbf{\square}$-lignin, •-hydroxy acids, ○-volatile acids, and $\square$-other organics

1. Contents of lignin, hydroxy acids, volatile acids, and other organics in BLs based on the total dissolved organics. For abbreviations, see Table I.
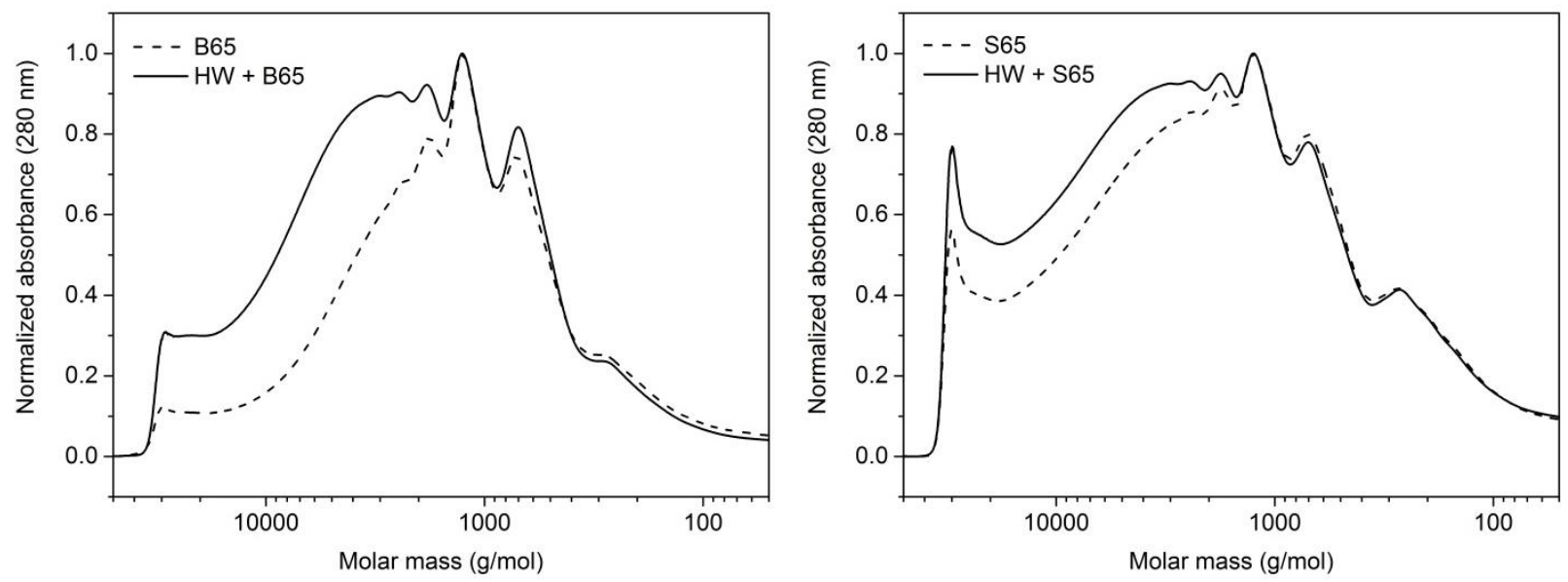

2. Molar mass distributions of dissolved lignin in black liquors from the kraft pulping of untreated and hot-water pretreated chips. For abbreviations, see Table I. 

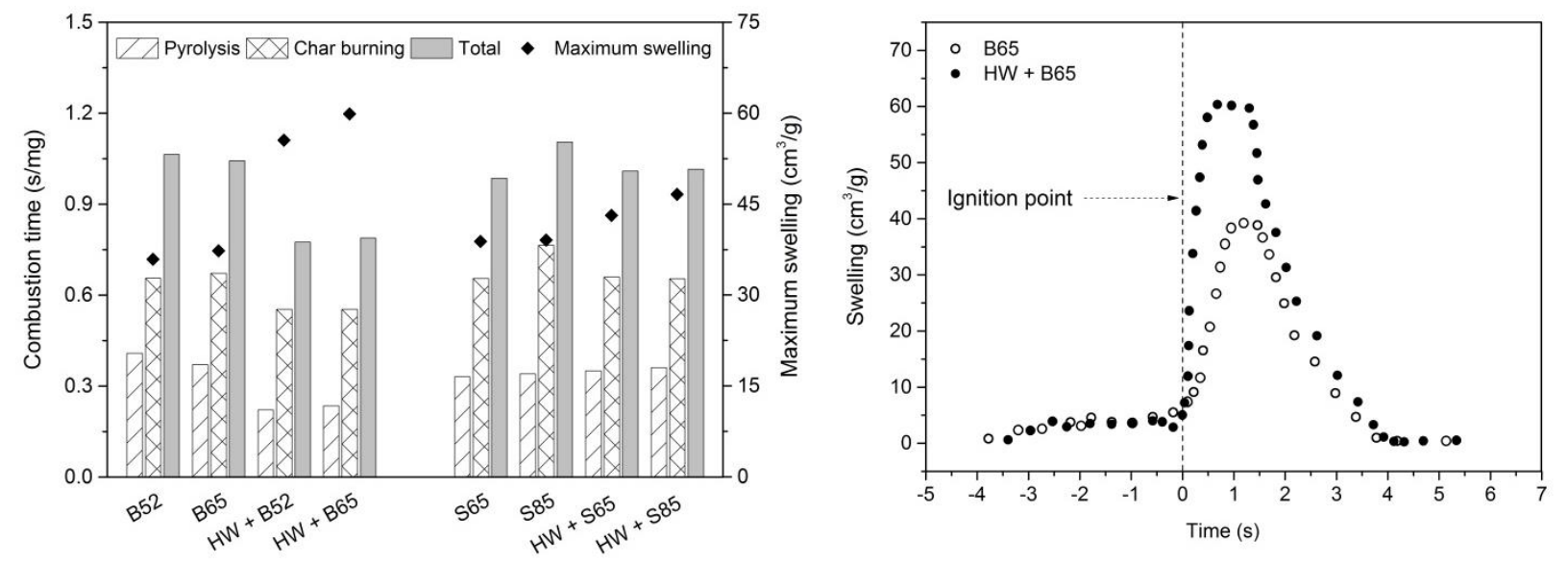

3. Combustion properties of kraft black liquors and the swelling profiles of two representative birch liquors. For abbreviations, see Table I. 